\title{
Real time and operational air quality forecasts in a power plant in Spain
}

\author{
R. San José ${ }^{1}$, J. L. Pérez ${ }^{1}$ \& R. M. González ${ }^{2}$ \\ ${ }^{1}$ Environmental Software and Modelling Group, \\ Computer Science School, Technical University of Madrid (UPM), \\ Campus de Montegancedo, Madrid, Spain \\ ${ }^{2}$ Department of Meteorology and Geophysics, Faculty of Physics, \\ Complutense University of Madrid; Ciudad Universitaria, Madrid, Spain
}

\begin{abstract}
Sophisticated and complex air quality models belonging to the so-called "third generation of air quality modelling systems" are nowadays to be adapted and implemented into state-of-the-art computer cluster platforms which allow an operational use of the air quality modelling systems for forecasting applications. This type of application allows a full control "in advance" of the impact on air quality concentrations of the emissions produced by different emission sources. In this application, a combined cycle power plant is used. Large industrial emissions located in the surrounding areas of cities are a substantial and important part of air concentrations in the surrounding areas of the city and industrial plant. In this contribution we show the implementation of an adapted version of the MM5-CMAQ - PSU/NCAR and EPA (US) models - modelling system for a large combined cycle power plant located in the near Madrid city (Spain). The system is implemented in an 8 - node cluster platform (Pentium -IV , 3,4 GHz) to provide in real-time the impact of the different power groups on the $\mathrm{O} 3, \mathrm{NOx}, \mathrm{PM} 10, \mathrm{SO} 2$ and $\mathrm{CO}$ air concentrations in accumulative mode and in forecasting mode for up to 72 hours in advance with a decision take-up period of about 16 hours. The air quality modelling system has been mounted over three model domains with $9 \mathrm{~km}, 3 \mathrm{~km}$ and $1 \mathrm{~km}$ spatial resolution respectively and 23 vertical layers (up to $100 \mathrm{mb}$ ) with a full emission model (EMIMO) to provide emissions in detail for these three areas covering up to 400 x $400 \mathrm{~km}$ for the mother domain and $24 \times 24 \mathrm{~km}$ for the $1 \mathrm{~km}$ spatial resolution model domain, all centered in the specific industrial plant (combined cycle power plant). The system called TEAP (EUREKA project) — a Tool to Evaluate the Air Quality Impact of Industrial Plants - allows one to quantify and qualify the impact of each individual power group (400 MW) in real-time and forecasting mode. As a consequence, the industrial plant and authorities have a period of time ( $\approx 16$ hours) to make the decision to switch off one power group or several, to minimize or avoid the possible exceedance of EU limits - as declared in the EU directives. The quantification of the impact of these possible exceedances of EU Directives due to the emissions produced by the power plant is essential to making decisions according to the daily forecasts.
\end{abstract}




\section{Introduction}

The simulation of the atmospheric process has had an important advance because of the improvement of the science knowledge and also because of the improvement of the capability of the computational platforms. The computer power has increased substantially in the last years and the PC based platforms have reached high performance levels. The cluster approaches open new scenarios for many applications and particularly on the atmospheric dynamics simulations. The atmospheric models have also reached high sophisticated levels which include the simulation of the aerosol processes and cloud and aqueous chemistry. These models include sophisticated land use information and deposition /emission models (San José et al. [7]). The atmospheric models include traditionally two important modules: a) meteorological modelling and b) transport/chemistry modules. These two modules work in a full complementary mode, so that; the meteorological module provides full 4D datasets (3D wind components, temperature and specific humidity) to the transport/chemistry modules. CPU time is mainly used for transport/chemistry $(70-80 \%)$. This modelling system require important initial and boundary data sets to simulate properly specific time periods and spatial domains, such as landuse data, digital elevation model data, global meteorological data sets, vertical chemical profiles and emission inventory data sets. In this experiment we have used AVN (NCEP/NOAA, USA) global meteorological information as input for the MM5 meteorological model. The emission inventory for the proper spatial domain and for the specific period of time (at high spatial and temporal resolution) is possibly the most delicate input data for the sophisticated meteorological/transport/chemistry models. The accuracy of emission data is much lower than the accuracy of the numerical methods used for solving the partial differential equation systems (Navier-Stokes equations) for meteorological models and the ordinary differential equation system for the chemistry module [7]. Typical uncertainty associated to emission data is 25-50\%. However, in our application it is more important to see the relative impact of the industrial emissions in the mesoscale domain - where the tested industrial plant is located - than to quantify and qualify the absolute pollutant concentrations in the atmosphere.

The emission inventory is a model which provides in time and space the amount of a pollutant emitted to the atmosphere. In our case we should quantify the emissions due to traffic, domestic sources, industrial and tertiary sector and also the biogenic emissions in the three model domains with $9 \mathrm{~km}, 3 \mathrm{~km}$ and $1 \mathrm{~km}$ spatial resolution mentioned above. The mathematical procedures to create an emission inventory are essentially two: a) Top-down and b) Bottom-up. In reality a nice combination of both approaches offers the best results. Because of the high non-linearity of the atmospheric system, due to the characteristics of the turbulent atmospheric flow, the only possibility to establish the impact of the part of the emissions (due to traffic or one specific industrial plant, for example) in air concentrations, is to run the system several times, each time with a different emission scenario. 
Examples of "state-of-the-art" meteorological models are: MM5 (PSU/NCAR, USA), RSM (NOAA, USA), ECMWF (Redding, UK), HIRLAM (Finnish Meteorological Institute, Finland), etc. Examples of "state-of-the-art" of transport/chemistry models - also called "third generation of air quality modelling systems" - are: EURAD (University of Cologne, Germany), [9], EUROS (RIVM, The Netherlands), [5], EMEP Eulerian (DNMI, Oslo, Norway), MATCH (SMHI, Norrkoping, Sweden), [2], REM3 (Free University of Berlin, Germany), [10], CHIMERE (ISPL, Paris, France), [8], NILU-CTM (NILU, Kjeller, Norway), [3], LOTOS (TNO, Apeldoorm, The Netherlands), [6], DEM (NERI, Roskilde, Denmark), [4], STOCHEM (UK Met. Office, Bracknell, UK), [1]. In USA, CAMx Environ Inc., STEM-III (University of Iowa) and CMAQ (EPA, USA) are the most up-to-date air quality dispersion chemical models. In this application we have used the CMAQ model (EPA, USA) which is one of the most complete models and includes aerosol, cloud and aerosol chemistry. In this application we will implement the MM5-CMAQ modeling system with EMIMO model over a power plant located in the South area of Madrid Community. The power plant has 4 different $400 \mathrm{MW}$ power groups and the cluster platform is designed in a way that it is possible to simulate the impact on air quality to disconnect a power group in accumulative way so that the $5^{\text {th }}$ scenario corresponds to the full emission switch off for the whole power plant. Figure 1 shows a scheme of the model domain architecture.

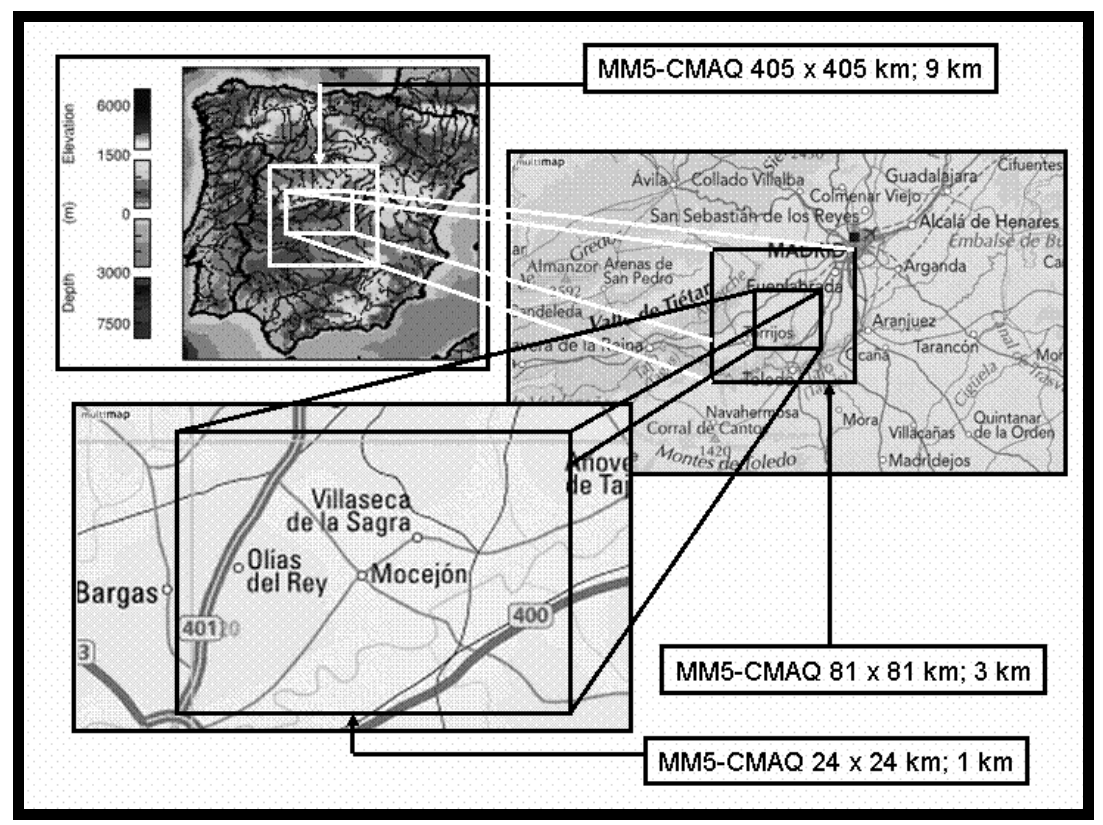

Figure 1: $\quad$ MM5-CMAQ-EMIMO architecture for this application. 


\section{Results}

The system is running under daily basis providing air quality forecasts for the different scenarios. Before the system is implemented we carried out a calibration process to assure the quality of the results. Figures 2 and 3 show some comparisons between observed and modelled data. On the other hand in Figure 4 we observe a view of the power plant Internet interface to provide daily forecasts for environmental authorities. In Figure 5 we show an example of the impact of disconnecting the four $400 \mathrm{MW}$ power groups in real-time at $20 \mathrm{~h} 00$ on April, 7, 2005 for NO2. Finally in Figure 6 we see an example for the scenario OFF3 with the impact of disconnecting 3 different 400 MW power groups simultaneously at $18 \mathrm{~h} 00$ on April 8, 2005.

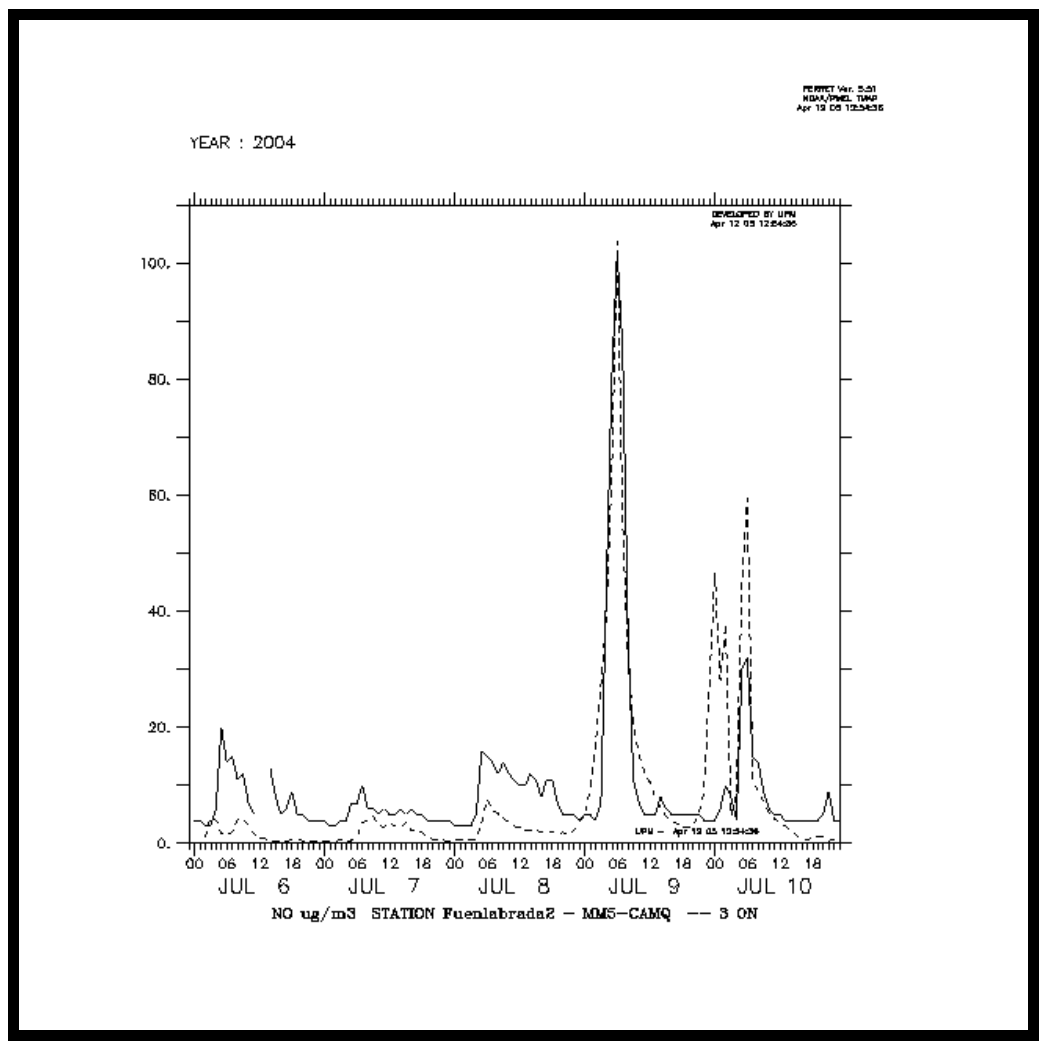

Figure 2: Comparison between observed and modeled NO concentrations in the Fuenlabrada 2 monitoring station. 


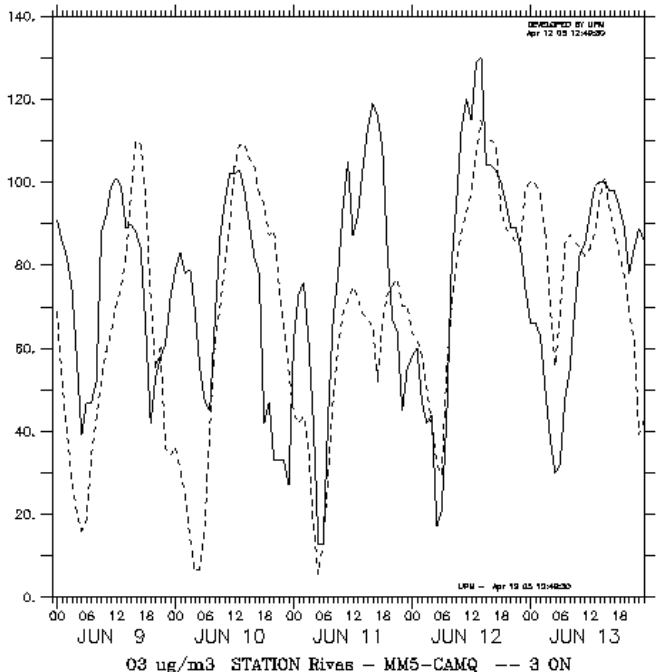

Figure 3: Comparison between observed and modeled NO2 concentrations in Rivas Vaciamadrid monitoring station.

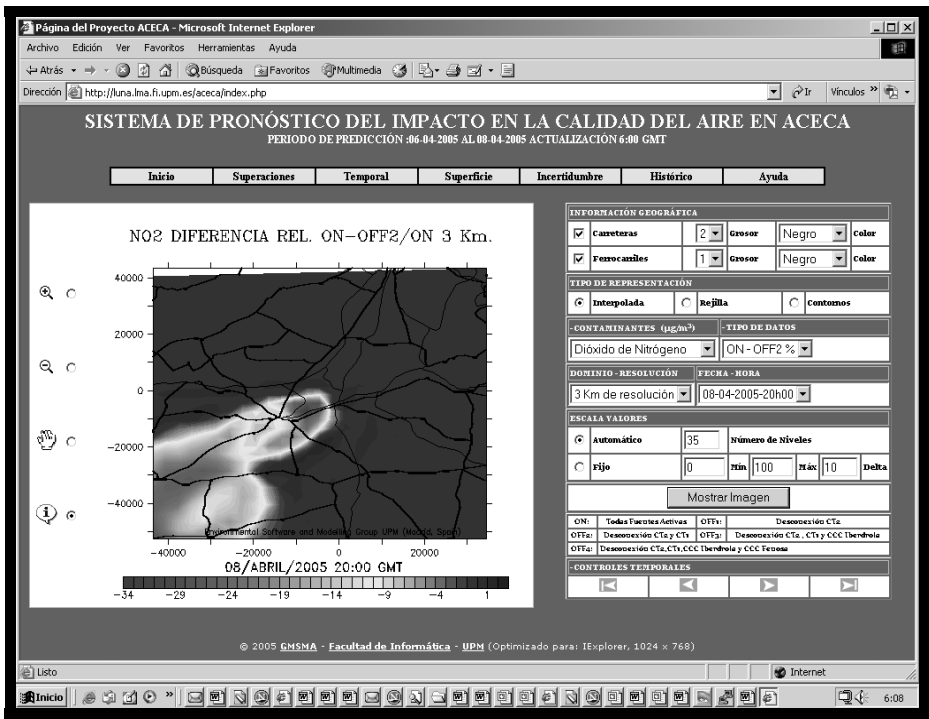

Figure 4: $\quad$ Power plant Internet interface to provide daily forecasts for the air quality impact of different power plant operational conditions. The relative differences for the ON-OFF2 / ON (\%) for the $3 \mathrm{~km}$ spatial resolution of the NO2 concentrations at 20h00 on April 8, 2005. 


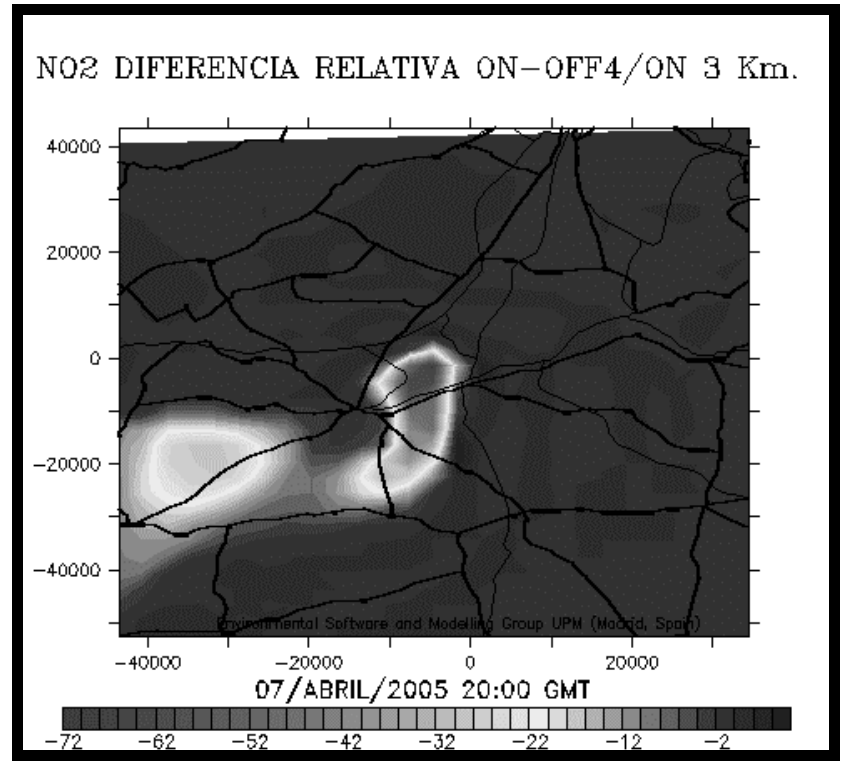

Figure 5: $\quad$ Relative differences (\%) on NO2 concentrations between $\mathrm{ON}$ and OFF4 scenarios by using TEAP tool for this power plant (Spain).

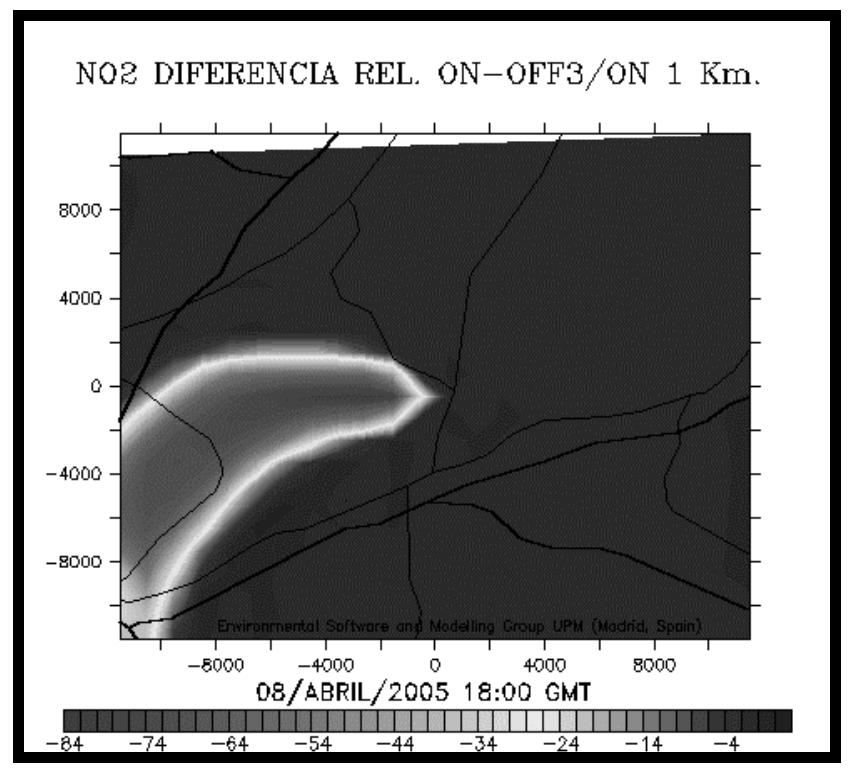

Figure 6: $\quad$ Relative differences between $\mathrm{ON}$ and OFF3 scenario in forecasting and real time mode on April 8, 2005 18h00 GMT for NO2 over the $1 \mathrm{~km}$ spatial resolution domain for the TEAP application in this power plant. 


\section{Conclusions}

The TEAP tool has been applied over a 4400 MW Spanish power plant located in the south area of Madrid. The results show that the TEAP tool provides an excellent performance for determining the air quality impact of the emissions corresponding to each $400 \mathrm{MW}$ power groups. The system has just started to operate and is under the testing phase.

\section{Acknowledgements}

We would like to thank Professor Dr. Daewon Byun formerly at Atmospheric Modeling Division, National Exposure Research Laboratory, U.S. E.P.A., Research Triangle Park, NC 27711 and currently Professor at the University of Houston, Geoscience Department for providing full documentation of CMAQ and help. We also would like to thank to U.S.E.P.A. for the CMAQ code and PSU/NCAR for MM5 V3.0 code. Also, we would like to thank Soluziona S.A. for funding this project.

\section{References}

[1] Collins W.J., Stevenson D.S., Johnson C.E. and Derwent R.G. (1997). Tropospheric ozone in a global scale3D Lagrangian model and its response to NOx emission controls. J. Atmos. Chem., 86, 223-274.

[2] Derwent, R. and Jenkin M. (1991). Hydrocarbons and the long-range transport of ozone and PAN across Europe. Atmospheric Environment 8, 1661-1678.

[3] Gardner R.K., Adams K., Cook T., Deidewig F., Ernedal S., Falk R., Fleuti E., Herms E., Johnson C., Lecht M., Lee D., Leech M., Lister D., Masse B., Metcalfe M., Newton P., Schmidt A., Vandenberg C. and van Drimmelen R. (1997). The ANCAT/EC global inventory of NOx emissions from aircraft. Atmospheric Environment 31, 1751-1766.

[4] Gery M.W., Whitten G.Z., Killus J.P. and Dodge M.C (1989), A photochemical kinetics mechanism for urban and regional scale computer modelling, Journal of Geophysical Research, 94, D10, pp. 12925-12956.

[5] Langner J., Bergstrom R. and Pleijel K. (1998). European scale modeling of sulfur, oxidized nitrogen and photochemical oxidants. Model development and evaluation for the 1994 growing season. SMHI report RMK No. 82. Swedish Met. And Hydrol. Inst., SE-601 76 Norrkoping, Sweden.

[6] Roemer M., Boersen G., Builtjes P. and Esser P. (1996). The budget of ozone and precursors over Europe calculated with the LOTOS model. TNO publication P96/004, Apeldoorn, The Netherlands.

[7] San José R., Prieto J.F., Castellanos N. and Arranz J.M. (1997) Sensitivity study of dry deposition fluxes in ANA air quality model over Madrid mesoscale area, Measurements and Modelling in Environmental Pollution, Ed. San José and Brebbia, pp. 119-130. 
[8] Schmidt H., Derognat C., Vautard R. and Beekmann M. (2001). A comparison of simulated and observed ozone mixing ratios for the summer 1998 in Western Europe. Atmospheric Environment, 35, 6277-6297.

[9] Stockwell W., Kirchner F., Kuhn M. and Seefeld S. (1977). A new mechanism for regional atmospheric chemistry modeling. J. Geophys. Res., 102, 25847-25879.

[10] Walcek C. (2000) Minor flux adjustment near mixing ration extremes for simplified yet highly accurate monotonic calculation of tracer advection. J. Geophys. Res., 105, 9335-9348. 